\title{
Un mortífero viaje en un cuento de Horacio Castellanos Moya ${ }^{1}$
}

\section{(A Fatal Journey in a Story by Horacio \\ Castellanos Moya)}

\section{Brenda Villalobos Varela²}

Universidad Nacional, Costa Rica

\section{RESUMEN}

El relato «Variaciones sobre el asesinato de Francisco Olmedo» se organiza a partir del eje temporal presente-pasado-presente. El narrador-personaje realiza un viaje en el que se comprueba que el pasado representa el reino de la mu erte, mientras que el presente se erige como el paraíso. El simbolismo muestra que el reino de la muerte-pasado corresponde a El Salvador, país de origen del protagonista, mientras que el paraíso presente son los Estados Unidos. Estas relaciones conllevan a una serie de implicaciones socioideológicas que el estudio describe.

\begin{abstract}
In the story "Variaciones sobre el asesinato de Francisco Olmedo," the time perspective evolves around the present-past-present continuum. The narrator-protagonist makes a journey in which it is verified that the past represents the kingdom of death, while the present is depicted as paradise. The symbolism reveals that the realm of death (past) is El Salvador, the protagonist's country of origin, while the United States depicts paradise (present). These relationships lead to a series of socio-ideological implications described in the present analysis.
\end{abstract}

Palabras clave: literatura centroamericana, narrativa salvadoreña, cuento salvadoreño contemporáneo

Keywords: Central American literature, Salvadoran narrative, contemporary Salvadoran stories

1 Recibido: 2 de diciembre de 2017; aceptado: 10 de mayo de 2018.

2 Escuela de Literatura y Ciencias del Lenguaje. Correo electrónico: brendavillalobos.cr@gmail.com

LETRAS 63 (2018), ISSN 1409-424X; EISSN 2215-4094 


\section{Introducción}

A Horacio Castellanos Moya, los especialistas como Rodrigo Cánovas $^{3}$, Leonardo Padura ${ }^{4}$ y Margarita Rojas 5 , han integrado a la denominada generación del cincuenta. Crea en sus escritos personajes abandonados en las oscuras calles de las grandes urbes, en las cuales no existen límites entre el bien y el mal; los crímenes forman parte del ambiente, al igual que la violencia generalizada que impide cualquier clase de nexo entre los personajes. En este sentido, la orfandad en los distintos ámbitos de la vida así como el desencanto, son aristas constantes en la obra del autor.

En El gran masturbador 6 , que reúne cinco relatos, Castellanos Moya explota, mediante su singular cinismo, los temas de la violencia, el dolor y el sinsentido. No obstante, con excepción de Rojas, ya mencionada, Squires y Manzoni ${ }^{7}$, no se ha profundizado con otras lecturas de tales textos.

Se presenta un análisis de «Variaciones sobre el asesinato de Francisco Olmedo» a partir del cual se muestran sus distintos planos de significación. Se parte de la hipótesis de que al realizar un viaje del presente al pasado, el narrador-protagonista intenta comprender y resolver su pasado y el de su pueblo que corresponde a la época de guerra en El Salvador; mas, mientras investiga lo ocurrido con Paco (su amigo de adolescencia) descubre que no hay manera de resolver un ayer rodeado de la muerte. El viaje es necesario para resolver situaciones inconclusas, pues ese ciclo no podría cerrarse hasta no llegar

3 Cánovas, Rodrigo. Novela chilena, nuevas generaciones. El abordaje de los huérfanos (Santiago: Pontificia Universidad Católica de Chile, 1997).

4 Leonardo Padura, «Miedo y violencia: la literatura policial en Hispanoamérica», Variaciones en negro (Bogotá: Norma, 2003).

5 Margarita Rojas González, La ciudad y la noche (San José: Farben, 2006) 593-604.

6 Horacio Castellanos Moya, El gran masturbador (San Salvador: Arcoiris, 1993); en adelante, la página se indica entre paréntesis.

7 Matthew Squires, «Horacio Castellanos Moya: El cinismo salvadoreño». The Kennesaw Tower: Undergraduate Foreign Language Research Journal II (2010); y Celina Manzoni, «Una narrativa al borde del abismo. Casi todos los cuentos de Horacio Castellanos Moya». Cuaderno de literatura 38 (2015): 450-461. 
a ciertas aclaraciones, pero la violencia no deja espacio al sentido o al entendimiento, y constata el narrador que no queda más que una absurda y escarnecedora muerte. Para el análisis se consideran las tesis teóricas de Vladimir Propp ${ }^{8}$ sobre la peregrinación del héroe de la vida a la muerte, entendiéndola como la representación del cierre de un ciclo para iniciar otro, o si se quiere, del proceso de cambio por el que pasa todo hombre a lo largo de su existencia. Además, se tienen en cuenta los presupuestos de Yuri Lotman ${ }^{9}$ sobre la estructura del texto artístico, ciertos conceptos propuestos por Gérard Genette ${ }^{10}$ y algunos intertextos presentes en el cuento, los cuales representan el viaje del narrador como su ingreso al reino de la no-vida de su pasado, no obstante, más allá de señalar las relaciones entre textos, es importante descifrar su significado con base a los espacios, el tiempo, personajes y acontecimientos del relato.

\section{Estructura}

El cuento se subdivide en tres historias ${ }^{11}$, insertadas entre sí, ocultas una dentro de la otra. La primera corresponde al presente del narrador-personaje en una oficina ubicada en Estados Unidos, que relata a su asistente los detalles de su retorno a El Salvador; la segunda, al pasado inmediato del narrador-personaje en El Salvador, en el que conversa con su amigo «el Chino» en una playa, mientras toman unos tragos, al igual que con otros amigos cercanos como Margarita y «Moncho», sobre el asesinato de Francisco Olmedo. La tercera es la reconstrucción del pasado lejano del narrador y los otros personajes en El Salvador, incluidos a Paco y las diferentes versiones sobre su muerte, en 1980.

8 Vladimir Propp, Raices históricas del cuento (1946) edición en español (México D.F.: Colofón, 1989).

9 Yuri Lotman, «Composición de la obra artística verbal», Estructura del texto artístico (1970) ed. (Madrid: Istmo, 1978) 261-293; y «El texto en el texto». La semiosfera (1981), ed. en español (Madrid: Cátedra, 1998) 91-109.

10 Gérard Genette, Figuras III (1970), ed. en español (Barcelona: Lumen, 1989).

11 La historia es, en términos de Genette, el contenido narrativo. 
El tejido de las historias da cuenta de un viaje realizado por el narrador-personaje a un pasado lleno de secretos y dudas, al igual que el texto mismo, que desde un principio se observa cual ardid, en tanto que se oculta una parte del relato, así la estructura textual es la siguiente:

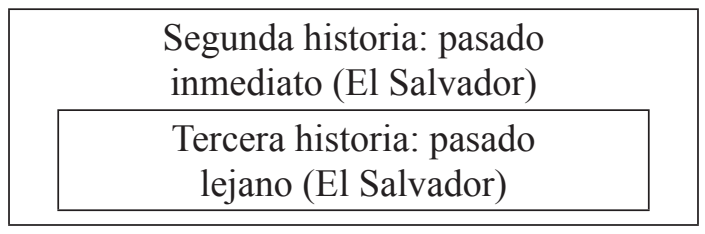

Sin embargo, terminando el texto se desprende la primera historia, que revela que todo lo que hasta entonces ha leído el lector lo ha contado desde el presente el narrador en Estados Unidos. Al respecto, se rompen los límites de los planos narrativos, dado que se incluye dentro del relato la narración ${ }^{12}$, poniendo a la vista de quien lee el proceso de creación literaria, y develando la estructura real del texto:

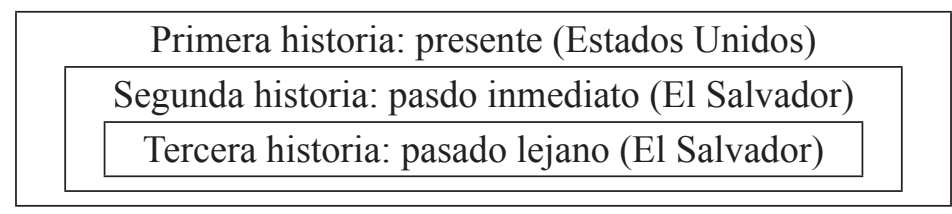

Relatados por un narrador intradiegético ${ }^{13}$ con focalización interna $^{14}$, las tres historias se entrelazan de manera engañosa, conformando una especie de enredadera que cubre, nubla y oscurece la memoria individual de los personajes a los que interroga el narrador: nadie recuerda nada, parecen irritarse cuando se les pregunta por lo sucedido y el ambiente hostil, mortífero y de traición en el que se encuentran, obstaculiza cualquier acercamiento a la verdad. En esta maraña de supuestos en la que se introduce el narrador para disipar

12 La narración es definida por Gérald Genette, como el acto narrativo productor y, por tanto, la situación real o ficticia en que se produce (83).

13 Un narrador intradiegético es aquel que forma parte del texto narrativo que produce.

14 La focalización interna se da cuando se conocen los hechos y la imagen de otros personajes desde la perspectiva del personaje en cuestión. 
las dudas sobre su pasado y el de su país de origen, concluye que no hay manera de resolver un pasado infernal, pues como se verá la travesía emprendida por el narrador señala su país de origen como el infierno, mientras que su lugar de residencia se analoga al paraíso, si se considera que allí se obtiene todo lo que en el pasado le fue negado, no hay muerte ni castigo, entre otros factores.

$\mathrm{A} 1$ regresar se encuentra el narrador -personaje con un lugar de castigos o torturas, mentiras y muerte, introduciéndose en un espacio tormentoso.

\section{El plano inferior}

El plano narrativo con el que empieza el texto - la segunda historia - se ubica en El Salvador. El primer lugar en el que se encuentran los personajes es el patio de la casa del Chino ubicada en la playa, en el cual «el sol se filtraba entre el follaje» (11) y asaba la barriga del narrador. Tanto la playa como el patio son espacios intermedios, que funcionan como un umbral entre un espacio y otro: el primero es un puerto por excelencia, lugar de encuentros y desencuentros, de llegadas y partidas, mientras que el patio divide la casa (el interior) de la ciudad (el exterior). Además, a las doce del día, pasan los personajes del patio al mar. Tanto espacial como temporalmente se alude observa a la transición, en tanto que ocurren los hechos en espacios que deben, necesariamente, ser transitados si desean los personajes llegar al otro lado; ocurre lo mismo con la hora, pues las doce horas son la mitad de un día. De este modo, héroe, espacios y tiempo se homologan representando mediante su relación, el paso de un estado a otro, el abandono de una identidad, en favor de un reinicio en el que el sujeto se reconstruye a sí mismo.

Al viajar el héroe o narrador protagonista de su país de residencia al de procedencia, y adentrarse en él, teniendo en cuenta que va de la costa hacia el centro de El Salvador, lo hace, en términos de Lotman, en el subespacio temporal del pasado, al que ya no pertenece. Sean 
cuales fueran las razones para retornar a El Salvador, el héroe se aleja de su hogar (Estados Unidos), desatendiendo las prohibiciones que se lo impedían (el destierro voluntario), para enterarse de «las cosas espeluznantes que este país hizo con sus hombres» (18). En cuanto llega se instala en el patio de la casa de el Chino y acepta los tres tragos que este le ofrece, al hacerlo «un relajamiento tremendo le iba ganando» (12) hasta quedarse dormido y despertar sintiéndose en "otro país» (16). Al ser el Chino el primer personaje con el que se encuentra el narrador, justamente en el primer lugar que visita, y ofrecerle los tragos y los pormenores de los acontecimientos relacionados con la muerte de Olmedo, el personaje cumple con la función de guía y protector de ese otro reino ajeno al narrador; es decir, El Salvador y el pasado. La casa se convierte en antesala del pasado lejano; la razón de que el Chino esté en ese lugar, no es otra que protegerlo de los agentes externos, de todo aquello que no pertenezcan al mismo. No obstante, al aceptar ingerir los alimentos del reino custodiado por su amigo y quedarse dormido, adquiere el narrador protagonista el derecho de ingresar en él, puesto que al hacerlo prueba que no tiene miedo de lo que proviene de ese lugar. Según Propp, el acto de beber es superar la prueba que el guardián impone al viajero para comprobar si pertenece o no al otro reino; si bebe, pasa a formar parte del reino del pasado; dormirse, por su parte, es prevalecer ante la prueba del sueño, ya que el sueño delata al viajero como perteneciente a la esfera de los vivos, pues los muertos no pueden dormirse.

Al despertar, animado por el Chino, cual Anticlea que se sumerge en el mar en busca del Hades al creer a su hijo muerto, también el personaje se sumerge en el reino de la no-vida de su pasado. Tras el baño en el mar, se adentra en una tierra que, aunque conocida, le es ajena; además de estar custodiada por el Chino, está resguardada por insectos que viven de la sangre; los zancudos «habían devorado» (14) parte de su muslo derecho. La marca de las picaduras es seña del ataque recibido, el estigma que indica su descenso al reino de la muerte, pues cuando sale el héroe del reino lejano, queda en su cuerpo 
una cicatriz que confirma la muerte o el ingreso al pasado. La marca puede ser una herida, el descuartizamiento, la amputación de un dedo o, como ocurre en este texto, las picaduras de los zancudos.

Ya en la civilización griega o en la tradición judeo-cristiana, la sangre es la llave del mundo después de la muerte o la moneda para ingresar al reino lejano. Tal como ocurre a Odiseo, quien al llegar al Hades lo asedian las almas que desean la sangre del cordero degollado, con el fin de recordar ${ }^{15}$, el personaje-narrador de «Variaciones sobre el asesinato de Francisco Olmedo» paga con su sangre el ingreso al pasado, pues en varias ocasiones «los zancudos estaban desatados, preparándose para un festín matutino» (11). La sangre ha sido el pago del recuerdo, en tanto que el narrador-protagonista paga con su sangre la información que sus amigos de juventud le brindan sobre el pasado.

Dentro del subespacio de El Salvador-pasado, no cesan los ataques, pues «montones de moscas que acechaban la mesa, el patio, el país inmisericorde» (12), las cuales parecen aumentar conforme avanza el texto, merodeaban a los personajes. La invasión de las moscas coincide con la concepción dantesca del infierno: en el primer círculo infernal, las almas sufren el castigo de ser «constantemente por moscas y avispas picados... y su sangre caía al piso para ser de gusanos el bocado ${ }^{16}$. Esta similitud intertextual explica la agresividad de los insectos contra los personajes, pues su presencia y los constantes ataques hacen alusión a los constantes castigos y torturas interminables en dicha zona.

Las descripciones del lugar reiteran la asociación El-Salvadorpasado-infierno. Se indica al inicio del texto que allí el calor asaba la barriga de los personajes, quienes caminaban por «la arena ardiente» (15) y se asfixian en los limitados espacios de los que no pueden moverse

15 Homero, Odisea, trad. de Luis Segalá Estalella (Barcelona: Bruguera, 1973).

16 La concepción que de este espacio tuvo el autor italiano es sumamente compleja, motivo por el cual La Divina Comedia ha sido considerada como una de las obras cumbres de la literatura universal. En dicho texto, el infierno se encuentra dividido en círculos según los pecados cometidos, en los cuales se encuentran las almas en pena y precisamente el primero de ellos está habitado por los insectos ya referidos. 
sin la autorización de «los animales» (apodo otorgado a los militares). Además, se encuentra en un plano inferior, pues desde ese lugar les es imposible mirar hacia arriba, porque el resplandor del sol «era casi hiriente» (12), ya que se hallan en la oscuridad (propiciada tanto por la ceguera que ocasiona el sol quemante como por el acontecer de los hechos durante el anochecer). Al rebuscar en su pasado, desciende el narrador a una especie de infierno, al pasado que quiso dejar de lado y del que no pudo escapar. La alusión a las quemaduras, el ardor y las tinieblas remite a la concepción infernal judeo-cristiana, al fuego que, según la Biblia, «no puede ser apagado» (Marcos 9:45). Para las almas condenadas, la luz divina es totalmente vetada, ya que mientras que la figura del Dios celestial, se ha asociado a la luz, el infierno se ha caracterizado por permanecer en las tinieblas. Tal como Dante, quien al ingresar al infierno fue empujado «a donde el sol no luce», y al intentar ver a Dios «no lo sufrió tan poco que no lo viera centellear en torno como del fuego el hierro sale candente», parecen haber sido condenados estos personajes a permanecer sin mirar la luz o al Dios celestial ${ }^{17}$.

Se plantea entonces el binomio entre un espacio superior y uno inferior, cada uno de los cuales se caracteriza en el texto mediante los contrarios luminoso-paradisiaco/oscuro-infernal. Los personajes atrapados en el país de procedencia del personaje-narrador, se encuentran en el plano inferior, es decir, el infierno mismo. Los personajes que habitan El Salvador constatan al infierno como lugar de residencia, puesto que se ajustan al perfil de las almas destinadas al castigo eterno. Tanto la concepción infernal del poeta italiano como las descripciones bíblicas coinciden en que habitan en el infierno almas pecadoras, de modo que lujuriosos, mentirosos, adúlteros, idólatras, herejes, asesinos y fornicarios, se encuentran distribuidos en distintos círculos, según su pecado. Los personajes son la encarnación de dichos delitos

17 En general, la estructura espacial de este cuento se divide en cielo e infierno, cuyas descripciones guardan gran relación tanto con las concepciones judeo-cristianas del mismo como con la estructura dantesca de Divina Comedia, criterios a los que se aludirá a lo largo del presente trabajo por ser arquetipos del mundo después de la muerte. 
divinos: Ezequiel, era «el ilusionista, el gran simulador, un delirante del verbo» (23), o sea, un mentiroso y además un ladrón; a Mercedes «le encantaba mamar verga y que se la metieran por el culo. Una degeneradita, caliente como pocas» (28), preferencias que la colocan dentro del grupo de los lujuriosos, al igual que Moncho, el narrador y Margarita, quienes se alejaron de Dios al sucumbir al deseo sexual fuera del matrimonio. Esto sin mencionar al asesino de Francisco Olmedo, quien es, desde la lógica judeo-cristiana, un pecador. Todas estas caracterizaciones aluden al no merecimiento de los personajes, quienes al igual que el espacio que habitan, son seres infernales, traicioneros déspotas y cómplices de la violencia.

¿Pero se encontraba libre de pecado el muerto y por eso no encajaba en dicho lugar o más bien fue su ofensa mayor que la del resto de personajes y por eso lo enviaron al más profundo de los círculos infernales? Si se tiene en cuenta la tercera historia - es decir, las distintas versiones que manejan los personajes sobre el asesinato de Francisco Olmedo- , tanto su hermana como sus amigos sienten cierto rencor hacia él e incluso consideran su asesinato como un merecido final. En palabras de Margarita, Paco era «un apátrida» (20) a quien le parecía una burla haber nacido en El Salvador, «un cobarde, que no supo aceptar que estaba destinado a ser un hombre decente» (22); por su parte, los amigos cercanos lo consideraban un traidor por haber cambiado su comodidad clasemediera para relacionarse con las clases sociales más bajas (Ezequiel y Mercedes); por último, Raquel (verdadera prostituta con quien Paco mantuvo una aventura), afirma que Paco «se limpió el culo con ella» (57) al traicionarla con otra mujer. Paco comete el peor de sus pecados: la traición contra su familia, contra su país, contra la persona a la que amaba; por tal razón es asesinado y víctima del peor de los castigos: el olvido. Al igual que Judas, quien tras traicionar a Jesucristo ha sido lanzado, según Dante, al último de los círculos del infierno junto a Satanás, Paco ha sido arrojado al olvido y la inexistencia. Al respecto conviene aclarar que el pecado de la traición también lo comete al narrador, pues él, al igual 
que Francisco Olmedo, abandona a todos sus conocidos. Comprender lo ocurrido con Paco es comprender lo que habría sido de él de no haber escapado del infierno mediante un exilio voluntario, quizás de allí esa necesidad de husmear en el pasado.

De este pasado infernal no puede escapar ningún personaje, pues todos están atrapados en la violencia que los destruyó, en tanto que se identifican por completo con los verdugos, los mentirosos y los ladrones, no obstante, el personaje-narrador se mueve entre un nivel narrativo y otro, pero ¿por qué tiene esa potestad? ¿Qué lo diferencia de sus amigos de infancia? Según Lotman, la totalidad del espacio textual está dividida en subespacios por un límite, cuya función principal es la impenetrabilidad; a partir de esto, dependiendo del subespacio asignado a los personajes, se les caracteriza como buenos o malos, adinerados o pobres, vivos o muertos ${ }^{18}$, si piensa que en el texto alude repetidamente a la no pertenencia del narrador a su país y que es este personaje el único en cruzar límites espaciales (solo él entra y sale del país), debe considerársele el héroe en términos de Lotman, ya que es de esos personajes a los cuales se les revelan como penetrables los subespacios asignados a otros ${ }^{19}$.

En la tercera historia, el narrador deja de formar parte de su país de procedencia (pasado-infierno); por ello, al volver investiga lo acontecido con su mejor amigo. Esta acción equivale a disipar las tinieblas y desprenderse de los lazos con su pasado; sin embargo, no hace más que reinventar lo ocurrido con Francisco Olmedo porque no puede «ver» la verdad. Vuelve a El Salvador para vacacionar (34), mas al llegar no hace sino investigar la muerte de Paco, y pronto comprende que él y sus amigos del pasado «pertenecíamos a mundos distintos y lo único que podía acercarnos era la recuperación de un cadáver mutilado, irreconocible» (18), al ser la muerte lo único que tienen en común él y sus compatriotas, «la reconstrucción de Paco fue el último intento por aferrarme a una tierra desde siempre ajena» (54),

18 Lotman, 281.

19 Lotman, 293. 
de la que además había sido «desterrado desde hacía tiempo» (18), de modo que el motivo de su retorno es «constatar que la mierda había crecido a borbotones, que mi decisión de vivir tan lejos, había sido quizá un gesto de sabiduría» (25). Vuelve el narrador para interpretar lo ocurrido con su tierra, con su gente y su pasado, y enterarse de lo que no ha visto con sus propios ojos y llenar ese vacío, no obstante, nadie recuerda nada o no están dispuestos a hablar, por ello no queda más que inventar una historia.

Tal como ha muerto Francisco Olmedo, desparecido hasta de la memoria, ha muerto y desaparecido el pueblo salvadoreño en los años de luchas entre guerrilleros y militares, por lo tanto, no tener claridad sobre lo ocurrido con Paco equivale a no comprender lo que ha ocurrido en El Salvador. La confusión de los personajes y su negativa a recordar o averiguar sobre el asesinato del amigo cercano, parece más bien un mecanismo de defensa: negar la muerte y la violencia permite seguir viviendo sin enfrentar la realidad, por el contrario, mirarla de frente y aceptarla es asumir su fatídico destino, o en palabras de Raquel que se está ya en el infierno y solo la soberbia impide reconocerlo (56). En el caso del narrador-protagonista, enterarse de lo ocurrido y comprender el deteriorado estado de sus amigos y su patria, es necesario para desprenderse del pasado, superar la muerte y replantearse lejos de la esterilidad y la no-vida de su país de procedencia.

La tercera historia, elaborada a partir del tejido de mentiras creadas por los personajes para no enfrentar la muerte, es la que muestra al texto cual ardid, pues están en ella una serie de marcas o huellas que la descubren cual artificio. En un principio expresa el narrador que había jugado con la hipótesis de que la guerrilla tuvo algo que ver con el asesinato de Paco «enfermo de historia, quizás para justificar mi prolongada ausencia del país» (13), y no en pocos apartados caracteriza lo afirmado como una alucinación, además de usar el futuro condicional para referirse a la situación, lo que expone los acontecimientos como hechos que no ocurrieron realmente, sino que «habrían ocurrido». Constantemente hace saber que lo ocurrido 
en esa historia, en la que cuenta las distintas versiones del asesinato de Paco, depende de su voluntad; un ejemplo es que cuando le hablan de la supuesta hija de Mercedes afirma: «opté por una niña de diez años, preciosa, color marfil, pelirroja» (30). Al usar la primera persona singular revela que es él quien está creando la historia, de allí que tenga la potestad de «optar» por una versión u otra.

La reconstrucción hecha por el narrador, en la que mezcla fragmentos de su pasado con especulaciones sobre lo que en su país ha ocurrido, expresa abiertamente que también son falsas las versiones de los diferentes personajes a los que entrevista. Sobre la versión de Margarita afirma que ella ha creado una imagen de Paco para desconcertarlo y que mucho de lo que ella decía «no encajaba» (20). Por otra parte, la versión de Moncho es falsa según Mercedes, y al final termina por enterarse el lector de que no existió ninguna Mercedes, ya que ese es un personaje ficticio creado por el narrador en un intento de explicar lo ocurrido y resolver el enigma de la muerte de Paco.

Los personajes son falsos, y los que no lo son no tienen un nombre, sino sobrenombres, lo que los expone como seres enmascarados, pues los seudónimos no hacen más que ocultar o intentar reemplazar el nombre real de los personajes. De este modo, nombres falsos, fantasmas de la mente, mentiras, secretos, contradicciones y dudas conforman la tercera historia, la cual es tan falsa como el narrador y lo que de su país ha quedado. Intentar «desenterrar al muerto» y explicar su partida es intentar explicar la verdad sobre su país y sobre sí mismo; no obstante, en el infierno no hay cabida para verdad alguna y nada se puede reconstruir en donde quedan «únicamente escombros, las paredes perforadas de bala, la infamia del aire enrarecido, ardiente» (55).

\section{El espacio superior}

Se ha afirmado aquí que el texto se divide en un plano inferior y uno superior. Mientras el primero se caracteriza por ser el pasado 
oscuro, mortífero, enclaustrante, estéril y violento, el segundo corresponde al presente luminoso, vívido y tranquilo. A lo largo de la historia, distintas culturas se preguntan sobre la vida después de la muerte. Desde la perspectiva occidental, al morir, el hombre tiene tres opciones determinadas según su comportamiento en el mundo de los vivos: el cielo, el purgatorio o el infierno. Así en la Divina Comedia, Dante emprende un viaje de ascenso desde el infierno al paraíso; el primero debajo del planeta y el segundo en el firmamento. Ahora bien, si El Salvador es el infierno en el que lujurioso, asesinos y mentirosos pagan sus culpas, ¿cuál sería el cielo, si es que lo hay? Dado que cada vez que se alude a la luz, esta viene de arriba, desde el sol, y que posee el narrador-protagonista objetos que tienen el color del oro, los cuales representan al paraíso, se asume que el presente del narrador en Estados Unidos corresponde al paraíso. El cielo o el paraíso se ha sido ubicado históricamente arriba, justo donde puede el ser humano ver al sol, el hecho de que el narrador-personaje descienda o baje desde Estados Unidos hasta el Salvador, constata la hipótesis de que ese primer espacio corresponde al paraíso.

El paraíso adopta las características geográficas, sociales y morales del mundo de los vivos según la cultura, en especial traslada el hombre al otro mundo sus intereses económicos (Propp 345). Dado que en El Salvador los hombres viven permanentemente atemorizados, explotados y castigados, se entiende por qué en Estados Unidos no hay carencia sino abundancia; no se ven los hombres forzados a producir, sino que se da el lujo de consumir, y los bienes que allí encuentran le aseguran la comodidad eterna. Tal parece que en este reino el ser humano puede disfrutar de la felicidad negada en el mundo de los vivos. En síntesis: en este espacio el narrador-protagonista tiene acceso a todo aquello que anheló en su pasado.

El narrador protagonista afirma poseer un brazalete de oro con incrustaciones de cristal, elemento típico del paraíso, que confiere poder sobre la muerte y la vida. Tener un objeto del otro reino (el brazalete de oro con diamantes), es señal de que el narrador ha estado allí, es 
más, a lo largo del texto se reitera una y otra vez que pertenece a Estados Unidos, espacio superior donde se encuentra el oro y el cristal.

A diferencia de las mujeres presentes en la segunda y tercera historia desarrolladas en El Salvador, que el presente (Estados Unidos) se asocian a la santidad; Linda es «inasible, impenetrable» (55), lo que la hace pura y digna del reino de los cielos según la Biblia, en la que específicamente se exhorta: «Huid de la fornicación. Todos los pecados que un hombre comete están fuera del cuerpo, pero el fornicario peca contra su propio cuerpo» (Corintios 6: 18), inmediatamente se da por entendido que quien no cumpla con dicho precepto no tiene cabida en el paraíso. Queda añadir que los católicos creen que la virgen María subió al cielo en cuerpo y alma, mientras que Dante concluye su viaje con la guía de Beatriz en el paraíso. De tales ejemplos se desprende la importancia que tiene la pureza de las mujeres para ingresar al reino del cielo.

El contraste Linda: pura-virginal/Margarita y Mercedes: fornicarias-lujuriosas, remite una vez más a la división entre cielo e infierno, dado que en el primer espacio se encuentra el narrador en presencia de una mujer que por impenetrable se distingue de las otras, precisamente es esa impenetrabilidad la que le da un carácter celestial, y reitera que el presente del narrador en Estados Unidos corresponde al cielo. Si a este contraste se suma la infertilidad, pues en El Salvador practican los personajes relaciones sexuales anales, en las que además «millones de espermatozoides se entusiasmaban hasta el delirio ante la proximidad de una competencia en la que no hay ganador, sustento de la muerte, del vacío» (39), en comparación con las figuras celestiales con las que no hay derrame y representan la vida eterna, el viaje realizado por el narrador no franquea los límites geográficos; vacacionar o visitar a los viejos amigos es el regreso doloroso a un pasado que necesita concluir, del que necesita desprenderse. Para ello es necesario comprender, mirar de frente los hechos y afrontar la violencia que ha arrasado con todo. Únicamente mediante una investigación lograría el narrador su propósito. Sin embargo, constata que no hay solución; 
el pasado violento no se puede explicar, de manera que al final del su viaje sabe lo mismo que al inicio sobre el enigma por resolver, lo que plantea el sinsentido de intentar hallar una explicación a lo ocurrido en el pueblo salvadoreño durante los años de guerra. 